Manuelle Medizin 2018 · 56:417

https://doi.org/10.1007/s00337-018-

0455-9

(c) Springer Medizin Verlag $\mathrm{GmbH}$, ein

Teil von Springer Nature 2018

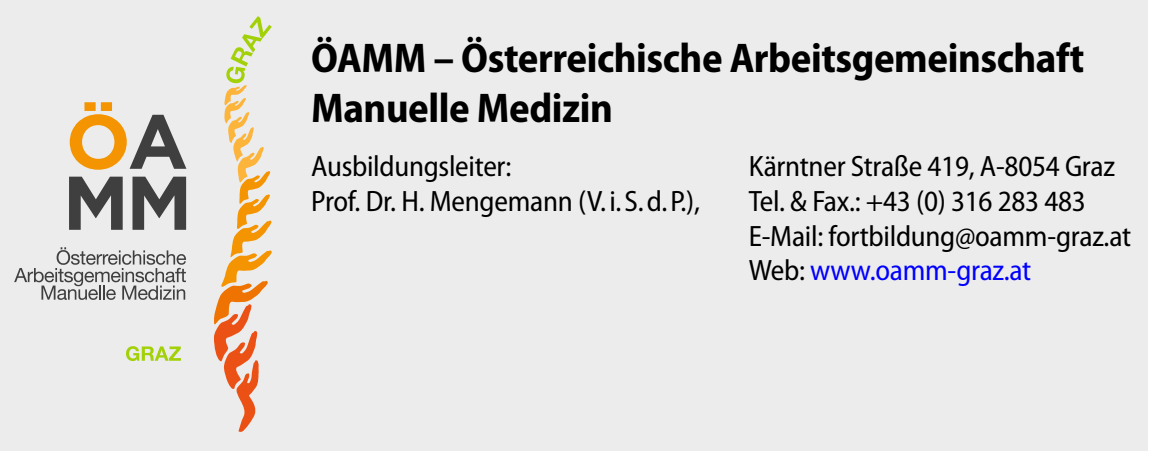

\section{Kurse 2018}

\section{Kurs 2}

11.10.-14.10./18.10.-21.10. Bad Häring

Kurs 3

$\begin{array}{llr}\begin{array}{l}\text { 20.10.-27.10.2018 } \\ \text { Kurs 5 }\end{array} & \text { Graz } & \text { KA1833 } \\ \begin{array}{l}\text { 01.12.-08.12.2018 } \\ \text { Refresher Wochenende }\end{array} & \text { Graz } & \text { KA1852 } \\ \begin{array}{l}\text { 11.11.-12.11.2018 } \\ \text { Loipersdorf }\end{array} & \text { KA1861 }\end{array}$

\section{Kurse 2019}

\section{Kurs 1}

$\begin{array}{ll}\text { 20.01.-27.01.2019 } & \text { Wien } \\ \text { 02.03.-09.03.2019 } & \text { Graz } \\ \text { 20.06.-23.06./27.06.-30.06. } & \text { Bad Häring } \\ \text { 21.09.-28.09.2019 } & \text { Graz }\end{array}$

\section{Kurs 2}

$\begin{array}{lll}\text { 12.01.-19.01.2019 } & \text { Graz } & \text { KA1921 } \\ \text { 05.05.-12.05.2019 } & \text { Wien } & \text { KA1922 } \\ \text { 29.06.-06.07.2019 } & \text { Graz } & \text { KA1923 } \\ \text { 10.10.-13.10./17.10.-20.10. } & \text { Bad Häring } & \text { KA 1924 } \\ \text { 07.12.-14.12.2019 } & \text { Graz } & \text { KA1925 }\end{array}$

\section{Kurs 3}

$\begin{array}{lll}\text { 28.02.-03.03./07.03.-10.03. } & \text { Bad Häring } & \text { KA1931 } \\ \text { 30.03.-06.04.2019 } & \text { Graz } & \text { KA1932 } \\ \text { 14.09.-21.09.2019 } & \text { Wien } & \text { KA1933 } \\ \text { 05.10.-12.10.2019 } & \text { Graz } & \text { KA1934 }\end{array}$

\section{Kurs 4}

02.02.-09.02.2019

07.09.-14.09.2019

\section{Kurs 5}

18.05.-25.05.2019

23.11.-30.11.2019

\section{Sonderkurse}

18.03.-22.03.2019
09.11.-10.11.2019

$\begin{array}{ll}\text { Graz } & \text { KA1941 } \\ \text { Graz } & \text { KA1942 }\end{array}$

Graz KA1951

Graz KA1952

St. Johann

Loipersdorf

\section{Ausbildungsziel}

Das Erlernen von klinisch-manuellen Untersuchungstechniken am Stütz- und Bewegungssystem zur therapeutischen Beeinflussung von reversiblen Funktionsstörungen.

Die Fortbildung dient damit der Erweiterung des Angebotes der kurativen, rehabilitativen und präventiven Medizin.

\section{Zielgruppe}

ÄrztInnen für Allgemeinmedizin und FachärztInnen aller Sonderfächer.

\section{Teilnahmevoraussetzung}

Frühest möglicher Beginn der Fortbildung ist nach der Promotion.

\section{Weiterbildungsdauer/Stundenerfordernis}

Mindestens 1,5 Jahre, nach den Richtlinien der Österreichischen Ärztekammer sind für das ÖÄK Diplom Manuelle Medizin insgesamt 300 Fortbildungsstunden (100 Stunden Theorie, 200 Stunden Praxis und Demonstrationen) erforderlich.

\section{Wesentliche Inhalte}

Erkennen und Behandeln mit den Händen

Von der Arbeitshypothese zur Diagnose

Prävention

Rezidivprophylaxe

Terminänderungen/Absagen vorbehalten.

Wir weisen darauf hin, dass für die Kursteilnehmer der ÖAMM die Kurszeiten und Anwesenheitspflicht bindend sind!

Die Bestätigung der Fortbildungspunkte durch die österreichische Ärztekammer ist an die Erfüllung der Kursrichtlinien gebunden.

Verbindliche Anmeldungen und Auskünfte im Sekretariat der ÖAMM E-Mail: fortbildung@oamm-graz.at Internet: www.oamm-graz.at Adresse: Kärntner Straße 419, $8054 \mathrm{Graz}$

Tel. \& Fax: +43 (0) 316-283 483 